\title{
Analyzing the key factors affecting the green supply chain management: A case study of steel industry
}

\author{
Hamideh Shekari $^{\mathrm{a}}$, Skandar Shirazi ${ }^{\mathrm{b}}$, Mohamad Ali Afshari ${ }^{{ }^{*}}$ and Said Mehdi Veyseh ${ }^{\mathrm{d}}$
}

${ }^{a}$ Department of Management, Payame Noor University, Taft, Yazd, Iran

${ }^{b}$ Department of Management, Payame Noor University, Hashtrood, Azarbijansharghy, Iran

${ }^{c}$ Department of Science, Kar University, Qazvin, Iran

${ }^{b}$ Department of Management, Payame Noor University, Tehran, Iran

A R T I C L I N F O AB S T R C T

\section{Article history:}

Received April 1, 2011

Received in Revised form

May, 15, 2011

Accepted 17 May 2011

Available online

19 May 2011

Keywords:

Supply chain

Factor analysis

Green supply chain management

\begin{abstract}
Green supply chain management (GSCM) has emerged as a proactive approach for improving environmental performance of processes and products in accordance with the requirements of environmental regulations. The aim of this paper is to determine and model the drivers of GSCM to put environmental activities into practice. Thirty-four measurement items are developed on the basis of opinions from industrial experts and the literature and the necessary data are collected. To validate the measurement scales for GSCM, we perform a factor analysis. The results show that a six-factor measurement model (including internal environmental management, green purchasing, cleaner production, recovery, eco-design and pollution) fits the data acceptably. All of the measurement items significantly loaded on the constructs on which they were hypothesized to load. These results gave us confidence that the measures are indeed valid and reliable.
\end{abstract}

\section{Introduction}

Today, environmental pollution is the main problem, which has the potential to lead to the extinction of humankind on earth if not addressed at this moment. Of the various kinds of pollution, air pollution is the one, which needs immediate attention. Global warming, an effect due to the increase in amounts of the green house gases present in air is the most severe problem mankind is facing at this moment. A green supply chains aims at confining the wastes within the industrial system in order to conserve energy and prevent the dissipation of dangerous materials into the environment. It recognizes the disproportionate environmental impact of supply chain processes within an organization (Ho et al., 2009).

Supply chain management (SCM) is to perform cooperation among a complex network of activities involved in distributing a finished product to the end-user or customer (Ninlawan et al., 2010). SCM is a process wherein raw materials are converted into final products and delivered to the end-

\footnotetext{
* Corresponding author. Tel. +989382029618

E-mail addresses: mohamadaliafshari@yahoo.com (M. A. Afshari) 
consumer (Fortes, 2009, p: 51). It is important to note, however, that we live in a world where environmental is an important issue to business practice. Since the early 1990's, manufacturers have been faced with pressure to address environmental management in their supply chains (Fortes, 2009, p: 51).

The traditional supply chain comprises five parts: raw material, industry, distribution, consumer, and waste. Each of the links in the supply chain can be a reason for pollution, waste, and other hazards to the environment. Regarding raw materials, a company may use environmentally harmful materials such as lead. However, organizations can put pressures on suppliers to use more environmentally friendly materials and processes.

With an increase pressures on environmental we expect the enterprises to implement strategies to reduce the environmental impacts of their products and services. To establish their environmental image, enterprises need to re-examine the objectives of their business. Success in addressing environmental items may provide new opportunities for competition, and new ways to add value to core business programs. Approaches, such as cleaner production, environmental management systems and eco-efficiency, have been implemented for green management practices. In 1994, the Confederation of British Industries (CBI) identified the factors driving the competitive advantage through environmental performance as market expectations, risk management, regulatory compliance and business efficiency. Green supply chain management (GSCM) plays a key role in ensuring that all of these factors are addressed. Environmental impacts occur at all stages of a product's life cycle. (Zhu et al., 2005, p: 450). Therefore, GSCM has appeared as an important component of business activities to help organizations develop 'win-win' strategies that achieve profit and market share objectives by lowering their environmental risks and impacts, while raising their ecological efficiency (Zhu et al., 2007).

This is not an easy task to do however. Adding the 'green' concept to the 'supply chain' concept adds a new paradigm where the supply chain will have a direct relation to the environment. This is interesting because, in history, these two paradigms were once in head-on collision with each other (Srivastava, 2007).

\section{Literature Review}

\subsection{Green Supply Chain Management}

Green supply chain management is an emerging field that strands out of the traditional supply chain perspective. The "quality revolution in the late 1980's and the supply chain revolution in the early 1990's” have sparked businesses to become environmentally conscious (Srivastava, 2007, p. 53). GSCM has gained popularity with both academics and practitioners to help reduce waste and preserve the quality of product-life and the natural resources. Eco-efficiency and remanufacturing processes are now important assets to achieve best practice. Global market demands and governmental pressures are pushing businesses to become more sustainable. Increasing government regulation and stronger public mandates for environmental accountability have brought these issues into the executive suites. (Fortes, 2009, p: 53). The literature in GSCM has been growing as organizations and researchers begin to understand that the management of environmental programs and operations do not end at the boundaries of the organization (Zhu et al., 2005, p: 451). GSCM's definition has varied from green purchasing to integrated supply chains flowing from supplier, to manufacturer, to customer and reverse logistics, which is "closing the loop” as defined by supply chain management literature (Zhu \& Sarkis, 2004). Similar to the concept of supply chain management, the boundary of GSCM depends on the goal of the investigator. In this paper, our focus is on a single level supplier-manufacturer-customer relationship.

All stages of a product's life cycle will influence a supply chain's environment burden, from resource extraction, to manufacturing, use and reuse, final recycling, or disposal. So green supply chain management is defined as "green procurement + green manufacturing + green distribution + reverse 
logistics". The idea of GSCM is to eliminate or minimize waste (energy, emissions, chemical /hazardous, solid wastes) along supply chain (Ninlawan et al., 2010).

There are different motivators for companies to switch to 'green' in their supply chain. Although some of the motivators are quite unclear. Some organizations are simply doing this because it is the right thing to do for the environment. Perhaps some are more radical to environmental change. Profitability and cost reduction are the other concerns for businesses to become 'green' in the supply chain (Darnall et al., 2008). The other issue is that GSCM practices are only about 'win-win relationships on environmental and economic performance' (Fortes, 2009, p: 57).

Supply chain greening initiatives have benefits on the level of the individual firm as well as on the national level. For individual firm GSCM programs distinct competitive advantages in terms of lower costs, greener products and better integration with suppliers (Gilbert, 2000). On a national level, GSCM can stimulate markets for green products, while also creates incentives for SMEs to adopt better environmental practices (Handfield et al., 2005).

From the definition of GSCM we can conclude that it involves green initiative in all of the stages of production from purchasing raw material to final customer. Therefore, some of the most important issues discussed in GSCM are green purchasing, green production, green market, green consumption and reverse logistics; and to do all these, we need green culture in our organization. The mentioned issues are discussed in following sections.

\subsubsection{Green purchasing}

In order to produce and supply green products from factories, we order big amounts of materials, office goods, and other products. Obviously, we need to purchase environmentally friendly products to be an environmentally friendly producer (Koshibu, 2001). Therefore, we need to include environmental issues in our negotiation with suppliers to maintain our market share and sometimes even just to survive. Green purchasing has been an important issue since early 90's (Hwa, 2001). Green purchasing consists of involvement in activities which include the reduction, reuse and recycling of materials in the process of purchasing (Ninlawan et al., 2010).

The business reasons for which companies adopt environmentally preferable purchasing practices to help improve the environment include (Huang, 2001):

- Responding to customer interest in environmentally friendly products and practices,

- Distinguishing a company and its products from competitors,

- Pursuing cost savings.

The general green purchasing principles consist of three primary principles (APO, 2001):

- The first principle is to ask buyers to consider the environmental impact of a product at all stages of its life cycle.

- The second principle recommends that buyers assess the overall environmental quality of manufacturers in terms of their environmental policies, management systems and overall performance.

- The third principle encourages buyers to collect as much environmental information as possible when purchasing products.

Zsidisin and Hendrick (1998) identified key factors for environmental purchasing such as providing design specification to suppliers that include environmental requirements for purchased items, cooperation with suppliers for environmental objectives, environmental audit for supplier's internal management and suppliers' ISO14001 certification. The concept of green purchasing which is becoming prevalent nowadays is closely related and encompassed by the concept of integrating suppliers with production and other operations. The driving forces for auto firms to integrate supplier involvement in their operations emerge as reducing emissions and hazardous waste through material substitution, pollution prevention and clean product design all of which require stronger relationships with suppliers. Once suppliers are involved as part of the organization, it can help broaden the existing knowledge of manufacturing process and thus makes it easier for the firm to adapt to new 
technology and develop environmental innovation (Rao, 2004). Most of the manufacturing business is quality driven and the corporations realize the need to integrate suppliers and business partners in the manufacturing program constituting process for: driving improvements, monitoring supplier performance, assuring the effectiveness of suppliers business and quality systems, matching technical roadmaps and recognition of supplier excellence (Trowbridge, 2003).

\subsubsection{Green production}

The greening of industry largely refers to the greening of production, as pollutants are largely generated during the production process of goods and services. Greening of production is associated with the following aspects of environmental protection (Rao, 2004):

- Reduction of pollution causing substances (e.g. solid and liquid wastes, air emissions, noise),

- Conservation of renewable and non-renewable natural resources

According to Rao (2004) there are four frameworks commonly used by the industry when we use the greening of production in factories which are as follows,

(1) Cleaner production: Cleaner production is a continuous application of an integrated preventive environmental strategy applied to products, processes and services addressing the causes of pollution. This approach aims to prevent pollution at its very source as opposed to the end of the pipe solution practiced in many places.

(2) Eco-efficiency: This approach is used for the conservation of the resources through producing goods and services by making optimal use of the inputs in the production process thereby minimizing waste and controlling pollution.

(3) Lean production: This concept, similar to eco-efficiency attempts to minimize non-value adding activities and reduce resource use which leads to increase the efficiency.

(4) Total quality environment management (TQEM): TQEM emphasizes waste minimization and process efficiency. The concept encompasses empowerment of employees, continuous improvement, and customer focus and supplier involvement.

For green production, we must maintain green manufacturing strategies. The mission of green production is create value by producing more or less effective tools for green manufacturing strategies through waste reduction, waste control, waste avoidance and waste prevention. The outcomes of these tools are zero pollution, zero defects, zero downtime and zero inventories (Dangayach \& Deshmukh, 2001).

\subsubsection{Green market}

It is not enough only for manufacturers to develop and supply green products into the market. Companies also badly need ecologically minded consumers or buyers who place a priority on purchasing green products. In other words, green companies need green markets (Koshibu, 2001).

\subsubsection{Green consumption}

In the 1980s and early 1990s, there has been increased awareness among consumers where their purchasing choices affect the environment. Consumers were urged to consider not only the quality of goods, but also the conditions under which goods are made (Yu, 2001).

\subsubsection{Reverse logistics}

Reverse logistics is the process of retrieving the product from the end consumer for the purposes of capturing value or proper disposal (Ninlawan et al., 2010).

\subsubsection{GSCM and organizational culture}

The movement towards sustainability largely depends on green culture. According to Harris and Cane (2002) green culture provides the issues to conceptualize green organizational culture values and it includes the following, 
- Organizations must incorporate environmental considerations throughout the entire organization.

- Such concerns should be considered throughout the value chain.

- Economic goals should be tempered.

- A short term perspective should be substituted with an intergenerational time frame.

- Spirituality, morality, smallness and futurity should be embraced .

- The environment should be afforded intrinsic valuation and respect.

\section{Methodology}

The aim of this paper is to determine the drivers of GSCM in order to put environmental activities into practice. We choose a cases study from an alloy steel industry located in Iran. The alloy steel company is a well-known and first alloy producer in Iran, established in 1994, and in the Middle East and one of the most advanced alloy steel producer in the world. Steel making plant, heavy section mill, light section mill, heat treatment and finishing plants of this company are equipped with modern facilities and the most updated know-how technology, which guarantees the best quality production of different alloy and special steel grades, based on international standards.

This type of industry has significant environmental and economic concerns within Iran and IT has faced increased pressures from the government and the public. These types of plants have to improve their environmental performance for survival. These companies in Iran have strong export product markets and have significant close relationships with foreign customers. Thus, experiences from this industry may be useful for other Iranian industries during their process of globalization.

Thirty-four measurement items were developed on the basis of opinions from industrial experts and the literature. The data used in this study consist of questionnaire responses from experts in Iran Alloy Steel, which includes items of GSCM. A total of 379 responses were received and to validate the measurement scales for GSCM, a factor analysis was performed.

\subsection{Determining the measurement items and Factor Analysis}

Thirty-four measurement items were developed on the basis of opinions from industrial experts and the literature. The measurement items are as follows:

1. Developing environmental and technical standards for purchasing raw materials (Webb, 2009, p: 34)

2. Adjust necessary rules for reduction of materials consumption (Stokes \& Tohamy, 2009, p: 8)

3. Using advanced technologies for optimizing energy consumption (Zhu et al., 2008b, p: 579)

4. Training right consumption patterns of energy (Zhu et al., 2005, p: 461)

5. Reduction of energy consumption (Zhu et al., 2005, p: 461)

6. Developing environmental and technical standards for purchasing machinery, equipments and instruments (Zhu et al., 2008a, p: 9)

7. Continuous check up of machinery and instruments erosion (Zhu et al., 2005, p: 458)

8. Check up of stages of manufacturing processes (Rao and Holt, 2005, p: 911)

9. Existence of advanced carrying system to reduce wastes (Zhu et al., 2005, p: 458)

10. Internal waste recovery (Shue, 2008, p: 20)

11. Soil, water and air pollution by products (Rao, 2004, p: 297)

12. Soil, water and air pollution by wastes (Rao, 2004, p: 303)

13. Soil, water and air pollution in the process of Internal recovery (Rao and Holt, 2005, p: 907)

14. Product recovery at the end of its life cycle (Stokes and Tohamy, 2009, p: 8)

15. Product life cycle (Stokes and Tohamy, 2009, p: 8)

16. Training personnel about environmental issues (Nuttall, 2008, p: 10)

17. Encouraging personnel to research about environment (Harris and Crane, 2002)

18. External waste recovery (Shue, 2008, p: 20)

19. Greening organizational culture (Harris and Crane, 2002) 
20. Environmental compliance and auditing programs (Chavan, 2005, p:446)

21. Fluidity of information (Zhu et al., 2007)

22. Support for GSCM from senior and mid-level managers (Zhu et al., 2008a, p: 9)

23. Total quality environmental management (Zhu and Sarkis, 2004; Vachon and Klassen, 2006)

24. ISO 14001 certification (Chavan, 2005, p:448)

25. Environmental management systems exist (Chavan, 2005, p:446)

26. Providing design specification to suppliers (Zhu et al., 2008a, p: 9)

27. Cooperation with suppliers for environmental objectives (Rao, 2004, p: 297)

28. Environmental audit for suppliers (Rao, 2004, p: 297)

29. Controlling Suppliers’ ISO14000 certification (Zhu et al., 2005, p: 453)

30. Green Packaging (Zhu et al., 2008b, p: 583)

31. Design of products for reduced consumption of material/energy (Avila, 2006)

32. Design of products for reuse, recycle, recovery of material, component parts (Chen and Shue, 2009, p: 668)

33. Design of products to avoid or reduce use of hazardous of products and/or their manufacturing process (Rao and Holt, 2005, p: 906)

34. Paying attention to the customer in product Design (Zhu et al., 2008a, p: 9)

3.1.1 Result

An exploratory factor analysis was conducted to derive grouping GSCM from the survey data. The Kaiser criterion was 0.889 and details of the results are shown in Table 1 and Table 2. According to Table 1, the Sig. of the test is less than 0.05 , which means the factor analysis could structuralize the construct of the research.

\section{Table 1}

KMO and Bartlett's Test

\begin{tabular}{llll}
\hline $\begin{array}{l}\text { Kaiser-Meyer-Olkin Measure of } \\
\text { Sampling Adequacy }\end{array}$ & $\begin{array}{l}\text { Bartlett's Test of Sphericity Approx. Chi- } \\
\text { Square }\end{array}$ & df & Sig. \\
\hline 0.889 & 89.11 & 105 & 0.000 \\
\hline
\end{tabular}

This factor analysis empirically grouped the scale items of GSCM into Six factors. The results show that a six-factor measurement model (including internal environmental management, green purchasing, cleaner production, recovery, eco-design and pollution) fits the data acceptably, see Fig. 4. The six factors can be labeled as follows:

The first factor, according to literature, is named as internal environmental management that is consisted of sub-factors 16, 17, 19, 20, 21, 22, 23, 24 and 25. In fact, this factor is the centrality of enterprises’ performance (Hsu \& Hu, 2008).

Zhu et al. (2008) emphasized that GSCM crosses all departmental boundaries within and between organizations and this so important and necessary for successful of environmental practices.

The second factor can be labeled as green purchasing and consists of measurement items 1, 26, 27, 28 and 29. Green purchasing was discussed in section 3.1 (Hua, 2001; Zhu et al., 2005).

The third factor is labeled as cleaner production and consists of measurement items 2, 3, 4, 5, 6, 7, 8, 9 and 30. Cleaner production was discussed in section 3.2 (Dangayach \& Deshmukh, 2001, p: 890; Rao, 2004).

The forth factor is labeled as recovery (reverse logistics) and consists of measurement items 10, 14, 15 and 18. Recovery refers to an organization's strategic use of recycling, redeployment, reselling and similar techniques to derive greater value from materials and products. Out-of-service equipment, excess inventory or raw materials, waste and process by-products and demolished facilities are 
included in these non-working assets. Recovery can be legitimately viewed as both an economically and environmentally beneficial practice (Zhu et al., 2008b, p: 580; Ninlawan et al., 2010).

Table 2

Results of factor analysis

\begin{tabular}{|c|c|c|c|c|c|c|}
\hline \multirow[b]{2}{*}{ Measurement items } & \multicolumn{6}{|l|}{ Constructs } \\
\hline & $\begin{array}{l}\text { Internal } \\
\text { environmental } \\
\text { management }\end{array}$ & $\begin{array}{l}\text { Green } \\
\text { purchasing }\end{array}$ & $\begin{array}{l}\text { Cleaner } \\
\text { production }\end{array}$ & Recovery & Eco-design & Pollution \\
\hline $\begin{array}{l}\text { Support for GSCM from senior and mid-level } \\
\text { managers }\end{array}$ & $0.98^{*}(12.45)$ & & & & & \\
\hline Total quality environmental management & $0.79(9.80)$ & & & & & \\
\hline ISO 14001 certification & $0.86(11.66)$ & & & & & \\
\hline Environmental management systems exist & $0.75(12.32)$ & & & & & \\
\hline Environmental compliance and auditing programs & $0.79(8.99)$ & & & & & \\
\hline Training personnel about environmental issues & $0.92(9.07)$ & & & & & \\
\hline $\begin{array}{l}\text { Encouraging personnel to research about } \\
\text { environment }\end{array}$ & $0.90(8.99)$ & & & & & \\
\hline Greening organizational culture & $0.87(9.07)$ & & & & & \\
\hline Fluidity of information & $0.92(8.99)$ & & & & & \\
\hline $\begin{array}{l}\text { Developing environmental and technical standards } \\
\text { for purchasing raw materials }\end{array}$ & & $0.95(13.08)$ & & & & \\
\hline Providing design specification to suppliers & & $0.82(22.94)$ & & & & \\
\hline $\begin{array}{l}\text { Cooperation with suppliers for environmental } \\
\text { objectives }\end{array}$ & & $0.92(14.50)$ & & & & \\
\hline Environmental audit for suppliers & & $0.88(12.77)$ & & & & \\
\hline Controlling Suppliers’ ISO14000 certification & & $0.78(20.72)$ & & & & \\
\hline $\begin{array}{l}\text { Developing environmental and technical standards } \\
\text { for purchasing machinery, equipments and } \\
\text { instruments }\end{array}$ & & & $0.80(22.23)$ & & & \\
\hline $\begin{array}{l}\text { Using advanced technologies for optimizing energy } \\
\text { consumption }\end{array}$ & & & $0.81(22.34)$ & & & \\
\hline Training right consumption patterns of energy & & & $0.77(24.08)$ & & & \\
\hline Reduction of energy consumption & & & $0.92(23.87)$ & & & \\
\hline $\begin{array}{l}\text { Adjust necessary rules for reduction of materials } \\
\text { consumption }\end{array}$ & & & $0.88(17.91)$ & & & \\
\hline $\begin{array}{l}\text { Continuous check up of machinery and instruments } \\
\text { erosion }\end{array}$ & & & $0.72(17.56)$ & & & \\
\hline Check up of stages of manufacturing processes & & & $0.87(24.08)$ & & & \\
\hline $\begin{array}{l}\text { Existence of advanced carrying system to reduce } \\
\text { wastes }\end{array}$ & & & $0.80(23.07)$ & & & \\
\hline Green Packaging & & & $0.71(18.80)$ & & & \\
\hline External waste recovery & & & & $0.88(20.21)$ & & \\
\hline Internal waste recovery & & & & $0.83(20.71)$ & & \\
\hline Product recovery at the end of its life cycle & & & & $0.66(19.45)$ & & \\
\hline Product life cycle & & & & $0.78(17.45)$ & & \\
\hline $\begin{array}{l}\text { Design of products for reduced consumption of } \\
\text { material/energy }\end{array}$ & & & & & $0.91(16.75)$ & \\
\hline $\begin{array}{l}\text { Design of products for reuse, recycle, recovery of } \\
\text { material, component parts }\end{array}$ & & & & & $0.90(22.86)$ & \\
\hline $\begin{array}{l}\text { Design of products to avoid or reduce use of } \\
\text { hazardous of products and/or their manufacturing } \\
\text { process }\end{array}$ & & & & & $0.83(21.84)$ & \\
\hline Paying attention to the customer in product Design & & & & & $0.75(21.14)$ & \\
\hline Soil, water and air pollution by products & & & & & & $0.87(18.86)$ \\
\hline Soil, water and air pollution by wastes & & & & & & $0.92(23.17)$ \\
\hline $\begin{array}{l}\text { Soil, water and air pollution in the process of Internal } \\
\text { recovery }\end{array}$ & & & & & & $0.82(23.08)$ \\
\hline
\end{tabular}

\section{* Loading factor (t-value)}

The fifth factor is named as eco-design and consists of 15, 31, 32 and 33 items. According to Zhu et al. (2008) the success of eco-design need the internal cross-functional cooperation and external cooperation with other partners overall the SCM. 
The last factor is labeled as pollution and consists of measurement items 11, 12 and 13 (Rao, 2004, p: 297).

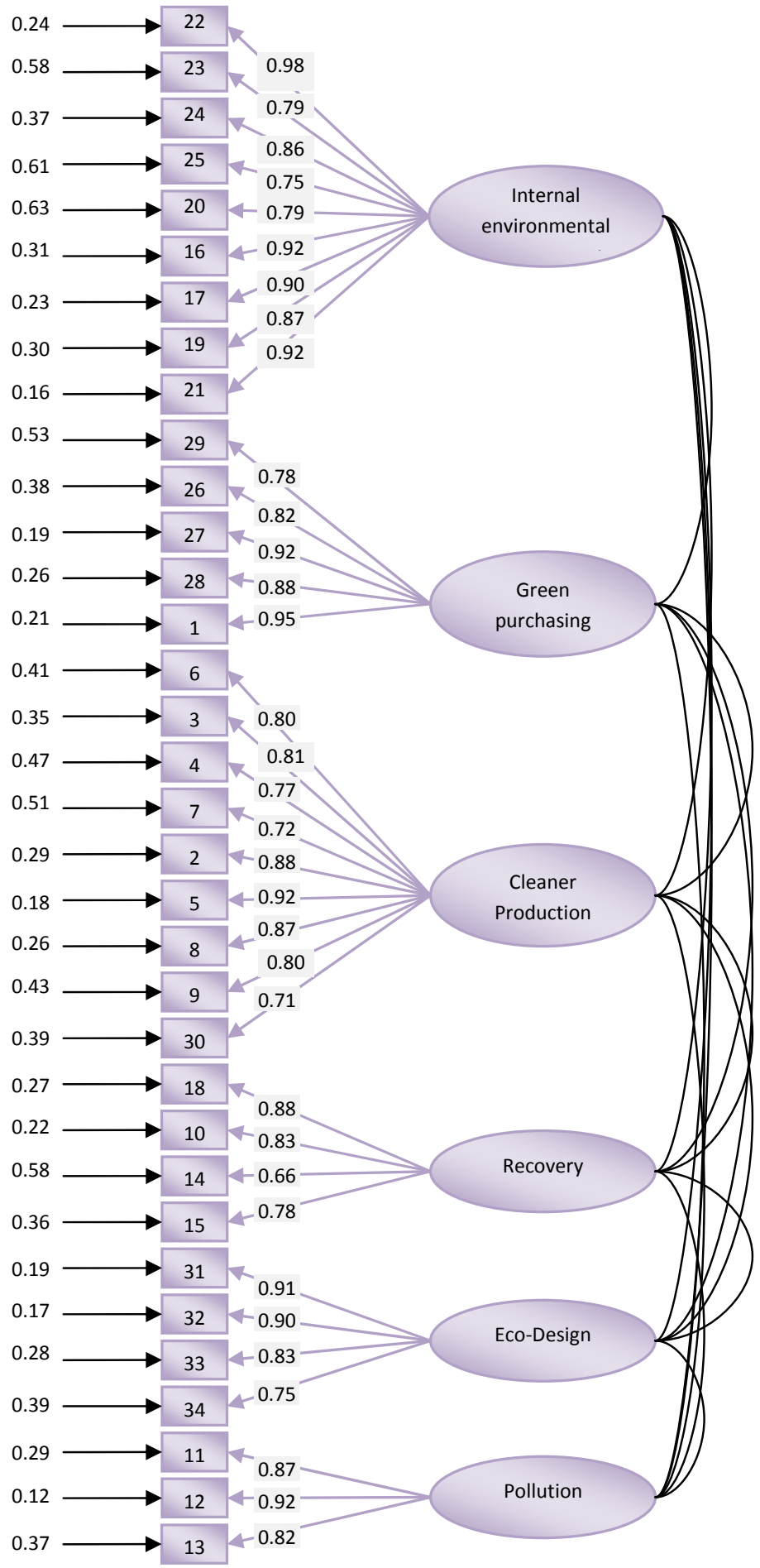

Fig. 1. GSCM factors

In Fig. 1 the columns from left to right indicate the residuals, item numbers and loading factors.The chi-square goodness-of-fit statistic was $\mathrm{P}^{*}(0.789)$ 89.11. Other statistics of fit are: $\mathrm{CFI}=0.98$; GFI = 
0.96; NFI $=0.97 ; \mathrm{RMR}=0.008 ; \mathrm{AGFI}=0.95 ; \mathrm{RMSEA}=0.013$. These statistics suggest that the data fit the measurement model reasonably well. In addition, we examined the patterns of the standardized residuals and these residuals have no impact on the model fitness.

Further analysis confirms the reliability of these six factors with Cronbach's alpha, of 0.84, 0.86, 0.78, 0.92, 0.86 and 0.83, respectively, for each group. All Cronbach's alpha values are well above the limit of 0.70 which ensure the constructs' internal consistency and validity.

\section{Conclusion}

Iranian organizations continue to struggle to improve their environmental image through cleaner production and investment in environmental protection. They seek to develop systematic and integrated approaches to environmental management such as industrial ecology and GSCM for moving towards closed-loop or cyclical industrial systems. GSCM has emerged as an important new archetype for companies to achieve profit and market share objectives by lowering their environmental risks and impacts and while raising their ecological efficiency. Iranian organizations have made some progress in adoption of GSCM practices. In this paper, we have presented a factor analysis to study the most important issues on GSCM practices for an alloy steel industry. The study of this paper has studied different known parameters, which existed in the literature and designed a questionnaire to gather decision makers' opinions.

Iranian companies have begun to change their focus from single plant improvements to the whole supply chains. However, GSCM is still a new concept in Iran. Some Iranian enterprises have recognized its importance and tried to put it into practice, but most of these enterprises may lack experience as well as necessary tools and management skills. In summary for improving the performance, Iranian manufacturing enterprises should develop necessary standards in material, machines, equipments, instruments purchasing and also in product and process designing; implement environmental standards such as ISO14000; reduce energy and material consumption; train employees about environmental issues, etc.

\section{References}

APO (2001), Green Productivity for Managers, A 2-Day Training Manual.

Avila, G. (2006). Product development for RoHs and WEEE compliance. Printed Circuit Design and Manufacture, 23(5), 28-31.

Chavan, M. (2005). An appraisal of environment management systems: A competitive advantage for small businesses. Management of Environmental Quality: An International Journal, 16(5), 444463.

Chen, Y. J., \& Shue, J. B. (2009), Environmental-regulation pricing strategies for green supply chain management. Transportation Research Part E, 45(5), 667-677.

Dangayach, G. S., \& Deshmukh, S. G. (2001). Manufacturing strategy literature review and some issues. International Journal of Operations and Production Management, 21(7), 884-932.

Darnall, N., Handfield, R., \& Jolley, J. (2008). Environmental management systems and green supply chain management: complements for sustainability?. Business Strategy and the Environment, 18, $30-45$.

Fortes, J. (2009). Green supply chain management: A literature review. Otago Management Graduate Review, 7, 51-62.

Gilbert, S. (2000), Integrated summary of the conference on “Greening Supply Chain”, May 25-27, 16.

Handfield R., Sroufe R., \& Walton S. (2005). Integrating environmental management and supply chain strategies. Business Strategy and the Environment, 14(1), 1-19.

Harris, L. C., \& Crane, A. (2002). The greening of organizational culture. Journal of Organizational Change Management, 15(3), 214-234. 
Hsu, C. W. \& Hu, A. H. (2008). Green supply chain management in the electronic industry, International Journal of Environmental Science \& Technology, 5(2), 205-216.

Huang, J. (2001). Eco-Efficiency and an overview of green productivity, Conference on Enhancing Competitiveness Through Green Productivity, China, 25-27 May.

Hwa, T. J. (2001). Green Productivity \& Supply Chain Management, Conference on Enhancing Competitiveness Through Green Productivity, China, 25-27 May.

Hiroaki, K. (2001). Greening the market: The effort by Fuji Xerox \& the green purchasing network, Japan, Conference on Enhancing Competitiveness Through Green Productivity, China, 25-27 May.

Krikke, H., Blanc, L.L., \& van de Velde, S. (2004). Product modularity and the design of closed-loop supply. California Management Review, 48 (2), 6-19.

Ninlawan, C., Seksan, P., Tossapol K. \& Pilada, W. (2010). The implementation of green supply chain management practices in electronics industry. Proceedings of the International Multi Conference of Engineers and Computer Scientists, Hong Kong, March 17 - 19.

Nuttall, N. (2008). Small and midsize firms moving toward green supply chains. Business and the Environment, 19, 381-390.

Rao, P. (2004). Greening production: a South-East Asian experience. International Journal of Operations \& Production Management, 24(3), 289-320.

Rao, P., \& Holt, D. (2005). Do green supply chains lead to competitiveness and economic performance?, International Journal of Operations \& Production Management, 25(9), 898-916.

Sarkis, J. (2003). A strategic decision framework for green supply chain management. Journal of Cleaner Production, 11(4), 397-409.

Sheu, J. B. (2008). Green supply chain management, reverse logistics and nuclear power generation, Transportation Research Part E, 44(1), 19-46.

Srivastava, S. (2007). Green supply-chain management: A state-of-the-art literature review. International Journal of Management Reviews, 9(1), 53-80.

Stokes, S., \& Tohamy, N. (2009), 7 Traits of a green supply chain, Supply Chain Management Review, 13, 722-752.

Trowbridge, P. (2003). A case study of green supply chain management at Advanced Micro Devices, Greenleaf Publication, Sheffield.

Vachon, S., \& Klassen, R. D. (2006). Green project partnership in the supply chain: the case of the package printing industry. Journal of Cleaner Production, 14, 661-671.

Webb, A. (2009). How green is my supply chain? Logistics and Transport Focus, 11.

$\mathrm{Yu}, \mathrm{N}$. (2001). The green consumption movement: The roles of government, business, academia, NGOs and Consumers, Conference on Enhancing Competitiveness Through Green Productivity, China, 25-27 May.

Zhu, Q., \& Sarkis, J. (2004). Relationships between operational practices and performance among early adopters of green supply chain management practices in Chinese manufacturing enterprises, Journal of Operations Management, 22(3), 265-89.

Zhu, Q., Sarkis, J. \& Geng, Y. (2005). Green supply chain management in China: pressures, practices and performance. International Journal of Operations \& Production Management, 25(5), 449-468.

Zhu, Q., Sarkis, J., \& Lai, K. H. (2007). Green supply chain management: pressures, practices and performance within the Chinese automobile industry. Journal of Cleaner Production 15, 10411052.

Zhu, Q., Sarkis, J. \& Lai, K. H. (2008a). Green supply chain management implications for closing the loop, Transportation Research Part E, 44, 1-18.

Zhu, Q., Sarkis, J., Cordeiro, J., \& Lai, K. H. (2008b), Firm-level correlates of emergent green supply chain management practices in the Chinese context, Omega, 36, 577 - 591.

Zsidisin, G. A., \& Hendrick, T. E. (1998). Purchasing's involvement in environmental issues: a multicountry perspective. Industrial Management \& Data Systems, 7, 313-20. 